\title{
HISTÓRIA DA EDUCAÇÃO ESPECIAL EM MANAUS: do Instituto Montessoriano Álvaro Maia (1943) ao Instituto Filippo Smaldone (1984)
}

\begin{abstract}
MÁRCIA DUARTE GALVANI
Doutora em Educação Escolar (UNESP, 2008). Especialista em Educação Especial (UNESP, 1999). Graduada em Educação Especial, com habilitação em Deficiência Mental (UFSM, 1999). Professora Associada do Departamento de Psicologia da Universidade Federal de São Carlos. Líder do Grupo de Estudos e Pesquisas sobre a Escolarização da Pessoa com Deficiência (GEPEPD-UFSCar). ORCID http://orcid.org/0000-0003-1092-746X.

E-mail: marciaduar@yahoo.com.br
\end{abstract}

\section{SAMUEL VICENTE}

Doutorando em Educação Especial (UFSCar). Mestre em Educação Especial (UFSCar, 2017). Licenciado em Pedagogia (UFMA, 2014). Técnico em Assuntos Educacionais da Universidade Federal do Amazonas (UFAM). Integrante do Grupo de Estudos e Pesquisas sobre a Escolarização da Pessoa com Deficiência (GEPEPD-UFSCar). ORCID: http://orcid.org/0000-0002-7205-9680. E-mail: samueljunior.ns@gmail.com 


\section{HISTÓRIA DA EDUCAÇ̃̃o ESPECIAL EM MANAUS: do Instituto Montessoriano Álvaro Maia (1943) ao Instituto Filippo Smaldone (1984)}

DO início do atendimento às pessoas com deficiência se deu por meio das instituições especializadas, considerando a atuação da iniciativa privada e o descaso do Poder Público com essa parcela da população. O presente estudo objetivou descrever e analisar a atuação das instituições especializadas no contexto da história da educação especial manauara, considerando o período de criação do Instituto Montessoriano Álvaro Maia (1943) ao Instituto Filippo Smaldone (1984). Verificou-se que as instituições especializadas criadas no âmbito manauara não apenas tiveram seu funcionamento vigente por meio do recebimento de auxílio financeiro do Poder Público, mas também por meio diversas ações realizadas que visavam arrecadar recursos para sua manutenção. Se em âmbito nacional, as normativas jurídicas trouxeram inúmeros desafios para a regulamentação da oferta dos serviços especializados, em Manaus podem-se observar essas demandas. Além disso, a história da Educação Especial no contexto manauara carece de dados mais aprofundados relacionados ao aspecto pedagógico da atuação dessas instituições especializadas, bem como as diferentes formas de encaminhamento das pessoas com deficiência a esses serviços especializados. Portanto, embora tenhamos como fator limitante o período de criação dessas instituições e a ausência de fontes históricas que possibilitem desvelar aspectos relevantes do cenário educacional local, há um profícuo espaço de atuação para os pesquisadores no campo da história da educação especial amazonense.

Palavras chave: Educação Especial. História da Educação. Política educacional.

\section{HISTORY OF SPECIAL EDUCATION IN MANAUS: from the Institute Montessoriano Álvaro Maia (1943) to the Institute Filippo Smaldone (1984)}

The beginning of care for people with disabilities occurred through specialized institutions, considering the performance of the private initiative and the neglect of the Public Power with this portion of the population. The present study aimed to describe and analyze the performance of specialized institutions in the context of the history of special education in manauara, considering the period of creation of the Instituto Montessoriano Álvaro Maia (1943) to the Instituto Filippo Smaldone (1984). It was verified that the specialized institutions created in the manauara framework not only had their operation in force through the receipt of financial assistance from the Public Power, but also through various actions that aimed to raise funds for its maintenance. If in the national scope, legal regulations have brought many challenges for the regulation of the provision of specialized services, in Manaus one can observe these demands. In addition, the history of Special Education in the context of manauara needs more in-depth data related to the pedagogical aspect of the performance of these specialized institutions, as well as the different ways of referring people with disabilities to these specialized services. Therefore, although we have as a limiting factor the period of creation of these institutions and the absence of historical sources that make it possible to reveal relevant aspects of the local educational scenario, there is a profitable space for researchers in the field of the history of special education in Amazonas.

Keywords: Special Education. History of Education. Educational politics. 


\section{HISTORIA DE LA EDUCACIÓN ESPECIAL EN MANAUS: del Instituto Montesoriano Álvaro Maia (1943) al Instituto Filippo Smaldone (1984)}

El inicio de la atención a las personas con discapacidad se dio por medio de las instituciones especializadas, considerando la actuación de la iniciativa privada y el descuido del Poder Público con esa parte de la población. El presente estudio objetivó describir y analizar la actuación de las instituciones especializadas en el contexto de la historia de la educación especial manauara, considerando el período de creación del Instituto Montessoriano Álvaro Maia (1943) al Instituto Filippo Smaldone (1984). Se verificó que las instituciones especializadas creadas en el ámbito manauara no sólo tuvieron su funcionamiento vigente por medio de la recepción de ayuda financiera del Poder Público, sino también por medio de diversas acciones realizadas que pretendían recaudar recursos para su mantenimiento. Si a nivel nacional, las normativas jurídicas traen innumerables retos para la regulación de la oferta de los servicios especializados, en Manaus se pueden observar esas demandas. Además, la historia de la Educación Especial en el contexto manauara carece de datos más profundos relacionados al aspecto pedagógico de la actuación de esas instituciones especializadas, así como las diferentes formas de encaminamiento de las personas con discapacidad a esos servicios especializados. Por lo tanto, aunque tengamos como factor limitante el período de creación de esas instituciones y la ausencia de fuentes históricas que posibiliten desvelar aspectos relevantes del escenario educativo local, hay un provechoso espacio de actuación para los investigadores en el campo de la historia de la educación especial amazonense.

Palabras-clave: Educación Especial. Historia de la Educación. Política educativa. 


\section{HISTÓRIA DA EDUCAÇÃO ESPECIAL EM MANAUS: do Instituto Montessoriano Álvaro Maia (1943) ao Instituto Filippo Smaldone (1984)}

\section{Introdução}

No contexto do atendimento às pessoas com deficiência havia o objetivo de oferecer tratamento médico e alívio da sobrecarga familiar e social. A educação desse público ficava reduzida a iniciativa da área médica e, ocorria geralmente em instituições religiosas ou filantrópicas, com o consentimento governamental, mas sem qualquer tipo de envolvimento do poder público. Esperava-se que as práticas educativas especiais curassem as deficiências, gerando comportamentos normalizados (PESSOTTI, 1984; MENDES, 2006).

A normalização foi nada mais do que um princípio defendido de que o deficiente pudesse dispor de condições de vida mais próximas de pessoas comuns (OMOTE, 1999). Esse princípio consolidou, no contexto brasileiro, ações governamentais que implementaram o ideário da integração, sob a égide de um argumento irrefutável de que "[...] todas as crianças com deficiências teriam o direito inalienável de participar de todos os programas e atividades cotidianas que eram acessíveis para as demais crianças" (MENDES, 2006, p. 388).

Aproximadamente na década de 1950, o descaso do Poder Público e a escassez de serviços de Educação Especial propiciaram o surgimento dos movimentos comunitários que se organizaram e implantaram redes de escolas especiais privadas filantrópicas (JANNUZZI, 2004; MENDES, 2006, 2010). Em 1954 foi fundada a primeira Associação de Pais e Amigos dos Excepcionais (APAE) no Rio de Janeiro, sendo também implantado no mesmo ano o primeiro atendimento educacional especializado para pessoas com superdotação, por Helena Antipoff (MAZZOTTA, 2005; JANNUZZI, 2004; BRASIL, 2008; MENDES, 2010; JANUZZI; CAIADO, 2013).

Na década de 1961, a publicação da Lei no 4.024/1961 fixou as diretrizes e bases para a educação nacional, apresentando em seu título X, artigos 88 e 89, diretrizes para a educação dos excepcionais. O artigo 89 dessa mesma lei assegurava o financiamento do Poder Público a qualquer iniciativa privada considerada "eficiente" pelos conselhos estaduais de educação, mediante oferta de bolsas de estudo, empréstimos e subvenções (BRASIL, 1961).

Para Mazzotta (2005) estava posta na legislação “[...] a mesma e velha questão da destinação das verbas públicas para a educação, comum ou especial, agravada pela indefinição da natureza 
do atendimento educacional” (MAZZOTTA, 2005, p. 69). Contudo segundo Mendes (2010), observa-se após a criação da lei, o crescimento das instituições privadas de cunho filantrópico. Sendo assim,

[...] o fortalecimento neste período da iniciativa privada, com instituições de natureza filantrópica sem fins lucrativos, se deveu primeiramente a uma omissão do setor da educação pública que forçou uma mobilização comunitária para preencher a lacuna do sistema escolar brasileiro. Ao mesmo tempo percebesse que estas instituições se tornaram parceiras do governo e foram financiadas com recursos provenientes da área de assistência social, o que permitiu exonerar a educação de sua responsabilidade (MENDES, 2010, p. 99).

Com o fortalecimento da iniciativa privada na oferta dos serviços especializados observase a proliferação de instituições que objetivavam receber financiamento do Poder Público para a execução de suas atividades. Um desses exemplos deve-se ao fato de que em 1962 haviam apenas 16 instituições filiadas à APAE.

Atualmente, conforme dados da Federação Nacionais das APAES, o quantitativo de instituições vinculadas consiste em mais de duas mil, atendendo a um público de aproximadamente 250 mil pessoas (FENAPAES, 2018). Sobre a configuração desses serviços na esfera privada, esse movimento configura-se talvez como "[..] o maior movimento filantrópico do país, agregando muitas instituições implantadas em muitos municípios brasileiros” (MENDES, 2010, p. 99).

Ao longo ha história da Educação Especial no Brasil temos observado que o debate sobre o delineamento dos serviços de Educação Especial foi se construindo então mediante a utilização dos termos Segregação, Integração, Inclusão. Ora, se no Brasil as instituições especializadas foram marcos históricos na oferta dos serviços de Educação Especial (MAZZOTTA, 2005; MENDES, 2010; FIGUEIRA, 2011; JANNUZZI; CAIADO, 2013), em Manaus não ocorreu de forma diferente.

A partir da década de 1960, passou a ser conveniente adotar a ideologia da integração, pela economia que ela poderia representar aos cofres públicos, tendo em vista que os gastos com os serviços de Educação Especial com caráter de segregação eram muito elevados. Esse custo alarmante dos programas paralelos especializados que segregavam os estudantes com deficiência, e a aglutinação de interesses de políticos, prestadores de serviços, pais e pessoas com deficiência possibilitaram a difusão da filosofia da normalização e integração (MENDES, 2006).

O início da institucionalização no Brasil ocorreu simultaneamente com o auge do discurso da normalização, discurso esse que para Rech (2010), buscou a padronização do indivíduo, 
na perspectiva de que os diferentes se tornassem parecidos com o modelo ideal de cidadão. Posteriormente, a filosofia da institucionalização passa a ser substituída posteriormente na década de 1990 pelo movimento da inclusão escolar, movimento esse que estamos vivendo no contexto atual da educação brasileira.

A Política Nacional de Educação Especial na Perspectiva da Educação Inclusiva preceitua a inclusão enquanto "[...] paradigma educacional fundamentado na concepção de direitos humanos que conjuga igualdade e diferença como valores indissociáveis [...]” (BRASIL, 2008, p. 1). Nesse cenário então, os objetivos de tal política seriam: (a) transversalidade da Educação Especial; (b) Atendimento Educacional Especializado - AEE; (c) escolarização nos níveis mais elevados; (d) formação de professores para o AEE e demais profissionais da educação; (e) participação da família e da comunidade; (f) acessibilidade; e, (g) articulação intersetorial nas políticas públicas.

Por sua vez Omote (1999) nos mostra que o termo inclusão apresenta avanços em relação à normalização e à integração. Segundo o autor, "as instituições especializadas também reproduzem as exclusões que ocorrem na sociedade" (OMOTE, 1999, p. 7). Entretanto, argumenta-se que a manutenção da instituição especializada poderia funcionar como um espaço de "convívio e socialização para os deficientes que, em função do grave comprometimento, não têm possibilidade de frequentar recursos de Educação Especial da rede regular de ensino" (OMOTE, 1999, p. 7).

Em estudos desenvolvidos não apenas em programas de pós-graduação do Amazonas, podemos destacar alguns que analisaram aspectos da política de inclusão escolar na rede pública municipal (MATOS, 2008; SANTOS, 2011; SILVA, 2013; CORRÊA, 2013; BATISTA, 2015; BRUCE, 2015; LIMA, 2016; VINENTE, 2017); estadual (MARQUES, 2010; SÁ, 2011; CARVALHO, 2012); privada (MORAES, 2011); e, federal de ensino (CARNEIRO, 2012; SOUZA, 2014).

Embora haja uma tendência em pesquisas sobre a temática da oferta dos serviços de Atendimento Educacional Especializado na capital amazonense, poucos estudos têm se debruçado a narrar a história desses serviços, contextualizando os aspectos nacionais da política com a conjuntura local. Embora observemos trabalhos que focalizaram a questão da formação de professores especializados e aspectos da organização pedagógica da escola para atendimento aos alunos com deficiência, pode-se observar uma lacuna na constituição da narrativa histórica da Educação Especial manauara.

Nos últimos anos, os trabalhos sobre Educação Especial no Amazonas tem tido um crescimento acentuado tanto na publicação de dissertações e teses, quanto no desenvolvimento de trabalhos de iniciação científica e outros tipos de projeto que vão se debruçando sobre a 
temática. Observamos por meio de um levantamento em teses e dissertações do Programa de Pós-Graduação em Educação (PPGE) da Universidade Federal do Amazonas (UFAM) uma preocupação dos pesquisadores em analisar aspectos da Educação Especial a partir do início da década de 1990 .

No entanto, em pleno século XXI ainda não fomos capazes de reconstituir em sua totalidade a história educacional amazonense. A região carece de estudos que constituam a trajetória da pesquisa e da política educacional na região. Assim, acreditamos que a Educação Especial enquanto modalidade de educação escolar no contexto amazônico desvela nuances em seus aspectos históricos e políticos.

Atualmente, o Estado do Amazonas possui várias organizações não governamentais, das quais podemos elencar: (a) Associação de Pais e Amigos dos Excepcionais - Apae; (b) Associação de Amigos do Autista no Amazonas - Ama/AM; (c) Associação Amazonense de Integração de Pais de Deficientes Mentais - Ademe; (d) Associação Pestalozzi do Amazonas; (e) Associação dos Deficientes Físicos do Amazonas (Adefa) e outras (ONGS BRASIL, 2017; VINENTE, 2017).

Observa-se no contexto da Educação Especial em Manaus que as instituições especializadas contribuíram, de certo modo, para a ampliação do atendimento aos estudantes com deficiência, principalmente no âmbito da Secretaria Estadual de Educação (SEDUC). Com a implantação de novas classes especiais no fim da década de 1980 foram firmados os primeiros convênios com instituições não governamentais, como a APAE, o Instituto Pestalozzi e associações de pais (MATOS, 2008; MARQUES, 2010; BATISTA, 2015; VINENTE, 2017).

Buscando então reconstituir o histórico de oferta dos serviços especializados em Manaus vamos considerar apenas as instituições pioneiras com fins educacionais. Pode-se elencar assim: o Instituto Montessoriano (1943), a Associação de Pais e Amigos dos Excepcionais (1973), a Associação Pestalozzi (1978), a Associação dos Deficientes Físicos do Amazonas (1980) e o Instituto Filippo Smaldone (1984). O presente estudo objetivou descrever e analisar a atuação das instituições especializadas no contexto da história da educação especial manauara, considerando o período de criação do Instituto Montessoriano Álvaro Maia (1943) ao Instituto Filippo Smaldone (1984).

\section{O instituto montessoriano álvaro maia (1943)}

Em Manaus, o início do atendimento às pessoas com deficiência ocorreu por meio da iniciativa privada, com a implantação do Instituto Montessoriano Álvaro Maia em 1943. O 
Instituto localizava-se em um sítio na Rua Paraíba, atual Avenida Jornalista Humberto Calderaro Filho e atendia crianças com as mais diferentes deficiências (NASCIMENTO; OLIVEIRA; MARINHO, 2007; BATISTA, 2015).

Em relatos feitos por Costa (2010), disponibilizados no sítio eletrônico do Recanto das Letras, podemos observar um pouco da descrição e organização do Instituto Montessoriano Álvaro Maia:

[...] mandou construir no jardim que havia em seu entorno, um relevo terrestre com lagos, montanha, rios etc., para o ensino de geografia. Com o auxílio do Governo do Estado, que pagava professores e lhes propiciava cursos de especialização em educação de surdos-mudos, fora do Estado Suas filhas, Rita Araújo (esposa de Umberto Calderaro Filho) especializou-se em trabalho com surdos-mudos e fez estágio com padre redentorista Eugênio, um do maiores especialistas no assunto, e Tereza Araújo, que especializou-se em método braile e as duas deram aulas no Instituto (s.p.).

Como pode ser observado, as ações pioneiras de Educação Especial desenvolvidas em Manaus, com início na década de 1940, eram filantrópicas. O Estado contribuía com a formação de professores e a Igreja Católica auxiliava com a promoção de cursos voltados para aperfeiçoamento das pessoas que atuavam na área da surdez. O fragmento a seguir apresenta traços da filantropia, marca dos serviços de Educação Especial ofertados inicialmente na cidade de Manaus:

Todo o trabalho do Instituto era mantido com a contribuição mensal através de um carnet. de comerciantes como J. G. Araújo, J. Rufino, J. S. Amorim, a ajuda de comerciantes do Mercado Municipal Adolfo Lisboa, que lhes dava alimentos e outros gêneros alimentícios, membros ilustres da sociedade e com a ajuda do Governo do Estado (COSTA, 2010, s.p.).

Mesmo que André Vidal de Araújo atuasse no âmbito do Poder Judiciário amazonense, pode-se observar ao longo dos relatos, a dificuldade em manter o Instituto Montessoriano em funcionamento. Dessa forma, o trabalho realizado era apoiado por doações que eram provenientes principalmente de comerciantes do Mercado Municipal Adolfo Lisboa, localizado no Centro Histórico de Manaus.

Além das doações recebidas em alimentos, o Instituto também contava com a contribuição de pessoas ligadas ao Poder Executivo local. Os relatos mostram que os surdos também se engajavam para manter o Instituto em funcionamento. 
Observa-se assim que André Vidal de Araújo era “[...] ajudado pelo surdo mudo Moacir, usando uma carroça puxada por um só cavalo, [...] recolhendo doações de alimentos. Não há notícias de que um só comerciante tenha se recusado à contribuição" (COSTA, 2010, s.p.).

Considerando o exposto, o Instituto Montessoriano encerrou suas atividades em 1974 (BATISTA, 2015). Até o momento não tivemos acesso a fontes históricas que nos permitam analisar os motivos que levaram ao fechamento da instituição. Infere-se com base nos dados que até a presente data o Instituto foi incorporado à Secretaria Municipal de Educação, tendo em vista que o endereço é o mesmo do prédio que, aparentemente, sediou o Núcleo de Educação Especial.

Outros estudos utilizando principalmente jornais impressos da época, poderão potencializar dados relevantes para a reconstituição do histórico desses serviços, bem como o quantitativo de estudantes atendidos na instituição e aspectos da qualificação dos profissionais que atuavam no local. Identificamos então a criação do Instituto Montessoriano como um dos marcos da história da Educação Especial no Amazonas e apontamos a necessidade de reconstituição dessa história.

\section{Associação de pais e amigos dos excepcionais - apae-manaus (1973)}

As primeiras instituições fundadas no Brasil que foram vinculadas à Associação de Pais e Amigos dos Excepcionais (APAE) localizavam-se nas regiões sul e sudeste do país. A primeira foi criada no Rio de Janeiro (1954) e as outras em Brusque - SC (1955) e Volta Redonda - RJ (1956). No contexto da capital amazonense, a APAE foi fundada em 4 de maio de 1973, estando autorizada pela APAE Nacional a utilizar a marca sob o registro ${ }^{\circ} 192$, de acordo com seu estatuto e usufruir de todos os direitos de Associação Filiada (FIDELIS; MIKI, 2017).

A APAE começou a funcionar reconhecida pelo Poder Público na categoria de escola a partir da publicação Resolução $n^{\circ}$ 102/94, do Conselho Estadual de Educação do Amazonas. Contava inicialmente com uma pequena equipe de professores, voluntários e alguns outros profissionais qualificados para trabalhar com esse público (FIDELIS; MIKI, 2017; FENAPAES, 2018).

Hoje, a APAE funciona em sede própria à Av. Perimetral $\mathrm{S} / \mathrm{N}$ - Conjunto Castelo Branco - Parque 10, zona centro-sul de Manaus. Segundo seu regimento, a instituição filantrópica apresenta um caráter cultural, assistencial e educacional sem fins lucrativos, tendo como finalidade promover medidas de âmbito municipal que visam não só ao desenvolvimento das potencialidades das pessoas com deficiência, mas também a inclusão destas na sociedade (APAE MANAUS, 2018). 
A APAE mantém a Escola Ilza Garcia ofertando serviços de Educação Especial, cuja especificidade só foi reconhecida no ano 2000. Possui 18 salas de aula de Educação Infantil, Oficinas Pedagógicas, Oficinas Profissionalizantes e salas de atendimentos (FIDELIS; MIKI, 2017; FENAPAES, 2018).

Sua equipe multidisciplinar é composta atualmente por professores, psicólogos, fonoaudiólogos, assistente sociais, fisioterapeutas, terapeutas ocupacionais, médicos e dentistas. A missão da APAE no Amazonas é "atender as pessoas com deficiência intelectuais e múltiplas, pela promoção e articulação de ações educativas para inclusão social, com ênfase nos direitos das áreas educação, saúde e assistência social” (FENAPAES, 2018).

Atualmente, a APAE Manaus mantém parcerias e convênios com vários segmentos da sociedade, oferecendo serviços de Assistência Social, Médica e Psicopedagógica. Considerando seu pioneirismo na oferta dos serviços de Educação Especial em Manaus, a instituição busca atuar como um referencial dentro do âmbito da Educação Especial no Amazonas.

Por meio dos registros históricos utilizados nesse estudo pode-se afirmar que reconstituir o histórico das instituições especializadas que ofertaram os serviços de Educação Especial nos séculos XIX e XX tem sido um desafio para os pesquisadores da área. Ao discutirem sobre a história da Associação de Pais e Amigos dos Excepcionais (APAE) em Manaus, Fidelis e Miki (2017) abordam sobre a necessidade de encontrar fontes de pesquisas organizadas que subsidiem a pesquisa histórica sobre as instituições educacionais para as pessoas com deficiência.

No contexto da produção científica não foi identificada nenhum publicação que descreva os serviços ofertados pela instituição, tampouco aspectos históricos sobre os atendimentos realizados. A análise sobre o tipo de trabalho realizado pelas instituições especializadas é necessário para compreender seu modus operandi.

Evidencia-se então amplo campo de pesquisa histórica em Educação Especial, considerando as instituições especializadas como objeto de estudo. Dessa forma, considerando que a APAE em Manaus seria atualmente a instituição mais antiga em funcionamento, considerando que o Instituto Montessoriano André Vidal de Araújo foi desativado, pode-se observar que à medida que novos estudos forem realizados, mais possibilidades teremos de contextualizar o histórico de oferta dos serviços especializados.

\section{Associação pestalozzi (1978)}

O Instituto Pestalozzi a nível nacional teve sua fundação no ano de 1926 (MAZZOTTA, 2005; JANNUZZI; CAIADO, 2013). Em Manaus, a Associação Pestalozzi é também uma 
entidade filantrópica, sem fins lucrativos, voltada a atender pessoas com deficiência, transtornos globais do desenvolvimento e funcionais. Foi criada em 1978, com a finalidade de garantir os direitos dessas pessoas, por meio do atendimento especializado e o fortalecimento de vínculos familiares.

No estado do Amazonas, o Governo do Estado por meio da Secretaria de Estado das Pessoas com Deficiência desenvolveu convênios com a Pestalozzi nos municípios de Boa Vista dos Ramos, Coari, Manaquiri, Maués, Manicoré, Manaus, Nova Olinda do Norte, Parintins e Tonantins (SEPED, 2015).

De acordo com o Plano de Trabalho da Instituição referente ao Edital n 001/2016/SEPED, a Associação Pestalozzi do Amazonas, ao ser fundada em novembro de 1978, teve suas primeiras reuniões realizadas na residência do Senhor Jorge Assad Aucar. Jorge era pai das fundadoras Vânia Aucar Seffair e Nádia Abdala Aucar (PESTALOZZI, 2016).

Segundo informações históricas contidas nesse Plano de Trabalho, Vânia Seffair era funcionária da Seduc e observou o crescimento da demanda de pessoas com deficiência, bem como a necessidade da criação de uma escola que atendesse a esses estudantes.

No ano de 1982 foram doados pela Superintendência da Zona Franca de Manaus (SUFRAMA) um terreno localizado no Bairro Distrito Industrial e uma verba para a construção da atual escola. Em junho de 1984 ocorreu a inauguração do prédio em um evento que contou com a presença do Ministro da Educação, à época Atílio Andreazza.

A instituição busca desenvolver ações que aumentem as potencialidades da pessoa com deficiência e de seus familiares, proporcionando serviços de educação especializada na Educação Infantil e oficinas pedagógicas através do Centro de Ensino Especial Helena Antipoff. Oferece atendimento especializado clínico, envolvendo atuação de profissionais como psicólogo,fonoaudiólogo, fisioterapeuta e assistente social.

A Pestalozzi de Manaus possui atualmente 150 alunos matriculados com diagnóstico de síndrome de Down, autismo, Acidente Vascular Cerebral (AVC), microcefalia, hidrocefalia, síndrome de Rett e Deficiência Intelectual (DI). Os professores da instituição foram cedidos pelas secretarias municipal e estadual de educação em Manaus. Os mesmos são especializados em Educação Especial e atendem aproximadamente 150 estudantes em um espaço localizado em área do Pólo Industrial de Manaus.

Essa entidade filantrópica operaciona suas ações mediante convênios com órgãos públicos, doações de amigos, voluntários e funcionários. Realiza diversos eventos para arrecadação de 
recursos tais como feijoada, bazar, feira de artesanato e festa junina. O ingresso de estudantes na instituição se dá por uma avaliação multidisciplinar realizada por assistente social, fisioterapeuta, médico e outros profissionais. Oferta atividades físicas, oficinas de artesanato, cursos laborais e oficinas pedagógicas. A Secretaria Municipal de Saúde (SEMSA) cedeu o clínico geral que atende na instituição.

Segundo informações da instituição, $80,58 \%$ do público atendido é formado por adultos; 12,13\% por adolescentes (13 a 17 anos) e 7,28\% por crianças (dos 6 aos 12 anos) (PESTALOZZI, 2016). Observa-se então que a maioria da população atendida pela instituição é de adultos com deficiência e transtornos globais do desenvolvimento.

Outras instituições atuam também junto a estudantes com deficiência intelectual. Tais como a Associação de Capacitação, Emprego e Renda do Amazonas (ACERPAM); a Associação de Pais e Amigos do Excepcional de Manaus (APAE); a Associação de Amigos dos Autistas do Amazonas (AMA-AM); e aAssociação Amazonense de Integração de Pais de Deficientes Mentais (ADEME), no entanto as atividades dessas instituições mais recentes serão descritas em outra publicação.

\section{Aassociação dos deficientes físicos do amazonas - adefa (1980)}

A Associação dos Deficientes Físicos do Amazonas (Adefa) foi fundada por Manuel Marçal de Araújo. A criação da associação ocorreu após um grave acidente, quando o fundado aos 28 anos ficou tetraplégico.

De acordo com informações disponibilizadas em seu blog, a Associação dos Deficientes Físicos do Amazonas (ADEFA) foi criada em 29 de julho de 1980. O sítio eletrônico dispõe sobre tal associação como uma entidade filantrópica sem fins lucrativos que "[...] vêm oferecendo às pessoas com deficiência, atendimento global, no intuito de melhorar a qualidade de vida e sua inclusão na vida produtiva e social do nosso estado" (ADEFA, 2018, s.p.).

Em 1989, Manuel Marçal elegeu-se vereador, cargo em que exerceu até o ano de 1992. Faleceu no ano seguinte, aos 56 anos, deixando um legado de luta no cenário amazonense à causa das pessoas com deficiência física (CORREIO DA AMAZÔNIA, 2015). Atualmente, a Associação conta com 9.750 sócios, dos quais, segundo informações da Adefa, 95\% estão abaixo da linha da pobreza. A Adefa foi considerada como instituição de utilidade pública mediante a publicação da Lei no 1.162 de 31 de outubro de 2007, aplicando-se no âmbito da Prefeitura de Manaus, as providências necessárias (MANAUS, 2007).

Ao longo dos anos a instituição também participou das ações do Plano Nacional de Qualificação das Pessoas com Deficiência, da Secretaria de Direitos Humanos da Presidência da República (SDH/PR). Com isso buscava garantir o acesso aos cursos oferecidos no SENAI 
(Serviço Nacional de Aprendizagem Industrial), no SESI (Serviço Social da Indústria) e no Sest Senat (Serviço Social do Transporte e Serviço Nacional da Aprendizagem do Transporte).

Sobre a atuação dessa instituição em âmbito educacional, até o momento, no contexto do Programa de Pós-Graduação em Educação (PPGE) da Universidade Federal do Amazonas (UFAM), ainda não há nenhuma pesquisa voltada para análise do papel desta e de outras instituições especializadas na oferta dos serviços de Educação Especial no município de Manaus. Observamos que no contexto histórico de oferta dos serviços especializados, a Adefa foi a primeira instituição do Amazonas voltada para atendimento das pessoas com deficiência física, enquanto no cenário nacional, o Lar-Escola São Francisco foi fundado em São Paulo no ano de 1943.

\section{Instituto filippo smaldone (1984)}

O Instituto Filippo Smaldone instalou-se em Manaus no ano de 1984, após tratativas realizadas entre familiares de surdos e a Congregação das Irmãs Salesianas dos Sagrados Corações em Belém-PA (MARQUES, 2010; INSTITUTO FILIPPO SMALDONE, 2018). Por meio de parceria entre o Arcebispo de Manaus Dom Milton Corrêa Pereira, o governador Gilberto Mestrinho e um grupo de pais, a primeira sede foi instalada na Rua Frei Lourenço, no centro da cidade.

As atividades escolares iniciaram-se no dia 15 de fevereiro de 1984, com oito alunos matriculados. Após a doação de um terreno, deu-se início a construção de uma sede mais ampla no Conjunto Campos Elíseos. Em 1994, houve o reconhecimento do Instituto Filippo Smaldone como uma Escola de Educação Especial, dada pelo Conselho Estadual de Educação (CEE).

De acordo com o sítio eletrônico do Instituto, sua missão é:

Proporcionar por meio da educação escolar, da cultura e da assistência social a promoção, a defesa e a proteção dos direitos de crianças e adolescentes surdos e com deficiência auditiva em idade escolar, em sua dimensão humanopsicológica e social, com atendimento escolar específico numa proposta bilíngue, com Língua de Sinais brasileira (LIBRAS), como primeira língua de instrução, e Língua Portuguesa, em sua modalidade escrita, como segunda língua (INSTITUTO FILIPPO SMALDONE, 2018, s.p.).

Observamos então, no contexto amazonense, mais uma vez, a destinação de recursos públicos para instituições especializadas, com caráter de filantropia. Assim, é possível identificar que a instituição insere como pauta demandas dos movimentos sociais para sua própria manutenção e reconfiguração de suas formas de atendimento. 
Em Manaus ganharam forças as ações desenvolvidas pelas instituições do Terceiro Setor. Nessa perspectiva, concordamos com Laplane, Caiado e Kassar (2016), quando as autoras afirmam que, se a presença do setor privado é reconhecida como colaboração importante para a efetivação de formas diferenciadas de atendimento, para o setor privado, a busca por recursos públicos é fundamental para sua existência.

Não podemos aqui negar a importância das instituições especializadas no atendimento às pessoas com deficiência, ainda mais quando observamos a ausência do Poder Público no tocante a oferta dos serviços especializados. Finalizando então esses retrospecto de atuação das instituições especializadas manauaras fundadas de 1943 até o início da década de 1980, deixamos um convite aos pesquisadores da área para reconstituir a história da educação especial manauara e amazonense.

\section{Considerações finais}

O presente estudo objetivou descrever e analisar a atuação das instituições especializadas no contexto da história da educação especial manauara, considerando o período de criação do Instituto Montessoriano Álvaro Maia (1943) ao Instituto Filippo Smaldone.

O início do atendimento especializado às pessoas com deficiência se deu por meio das instituições especializadas, considerando a atuação da iniciativa privada, no qual temos como marco temporal na cidade de Manaus a criação do Instituto Montessoriano Álvaro Maia em 1943.

Cabe aqui sintetizar que as instituições especializadas criadas no âmbito manauara não apenas tiveram seu funcionamento vigente por meio do recebimento de auxílio financeiro do Poder Público mas também por meio diversas ações realizadas que visavam arrecadar recursos para sua manutenção.

Verificamos que em âmbito nacional, o texto legal trouxe inúmeros desafios para a regulamentação da oferta dos serviços especializados. Dessa forma, o local no qual os serviços de Educação Especial deveriam então ser ofertados tornou-se a mola propulsora de um intenso debate nesse campo.

Tal debate teórico implicou em duas questões, a primeira era se essa escolarização deveria ocorrer toda em escolas especializadas públicas da rede regular de ensino; a segunda baseava-se na oferta desse atendimento especializado em instituições privadas que ofertavam os serviços de Educação Especial. 
Observa-se então que diversos agentes disputam espaço no campo das ideias e na arena política para que os dispositivos legais publicados contenham as proposições de determinados grupos mobilizados socialmente e politicamente. As críticas dadas, ao longo do tempo, aos serviços de Educação Especial ofertados pelas instituições dizem respeito a pouca ênfase na questão pedagógica do ensino ministrado.

A história da Educação Especial no contexto amazonense e manauara carece de dados mais aprofundados relacionados ao aspecto pedagógico da atuação dessas instituições especializadas, bem como as diferentes formas de encaminhamento das pessoas com deficiência a esses serviços especializados.

Caberiam como questões norteadoras para a realização de outros estudos os seguintes questionamentos: (a) quais os registros impressos das instituições de educação especial que ofertaram esse serviço no período abordado? (b) como a sociedade civil participava no fortalecimento dessas instituições? (c) qual o papel desempenhado pelo Poder Público para assegurar a manutenção desses serviços ao longo dos anos? e, (d) Como as instituições manauaras foram reagindo às disposições legais nacionais que foram publicadas nesse período?

Não pretendendo esgotar todas essas questões em apenas um trabalho, esse estudo pode contribuir para a avaliação de políticas públicas no cenário manauara, apontando aspectos históricos dos serviços especializados ofertados ao longo dos últimos anos. Embora tenhamos como fator limitante o período de criação dessas instituições e a ausência de fontes históricas que possibilitem desvelar aspectos relevantes do cenário educacional local, há um profícuo espaço de atuação para os pesquisadores no campo da história da educação especial amazonense.

\section{REFERÊNCIAS}

ADEFA. Associação dos Deficientes Físicos do Amazonas. Instituição que visa inserir os Deficientes físicos em âmbito global. Disponível em: <http://adefaam.blogspot.com.br/>. Acesso em: jan. 2018.

APAE MANAUS. Apae: últimas notícias. Disponível em: <http://manaus.apaeam.org.br/>. Acesso em: maio 2018.

BATISTA, C. P. Política pública de inclusão: atendimento de educandos com deficiência visual no município de Manaus/AM. 2015. 123f. Dissertação (Mestrado em Educação) - Faculdade de Educação, Universidade Federal do Amazonas, Manaus, 2015.

BRASIL. Decreto $n^{\circ} 7.611$, de 17 de novembro de 2011: dispõe sobre a educação especial, o atendimento educacional especializado e dá outras providências. Diário Oficial [da] República Federativa do Brasil, Brasília, DF, 17 nov. 2011. 
. Lei $n^{\circ}$ 4.024, de 20 de dezembro de 1961: fixa as diretrizes e bases da educação nacional. Diário Oficial [da]República Federativa do Brasil, Brasília, DF, 20 dez. 1961.

. Política Nacional de Educação Especial na Perspectiva da Educação Inclusiva. Diário Oficial [da] República Federativa do Brasil, Brasília, DF, jan. 2008.

BRUCE, C. C. A política de educação inclusiva: a Tecnologia Assistiva como possibilidade de participação e aprendizagem de alunos com deficiência física na escola. 2015. 87f. Dissertação (Mestrado em Educação) - Faculdade de Educação, Universidade Federal do Amazonas, Manaus, 2015.

CARNEIRO, C. R. Análise da acessibilidade urbana em Manaus: um olhar sobre a criação de espaços acessíveis para a pessoa com deficiência. 2012. 170f. Dissertação (Mestrado em Psicologia) - Faculdade de Psicologia, Universidade Federal do Amazonas, Manaus, 2012.

CARVALHO, J. L. B. Promoção da saúde em Ensino Fundamental: ações de Teleducação em Fonoaudiologia na inclusão escolar. 2012. 113f. Dissertação (Mestrado em Ciências - Fonoaudiologia) Faculdade de Odontologia de Bauru, Universidade de São Paulo, Bauru, 2012.

CORRÊA, R. M. A formação continuada do professor para a educação de surdos na rede municipal de Manaus: repercussões na prática pedagógica. 2013. 135f. Dissertação (Mestrado em Educação) Faculdade de Educação, Universidade Federal do Amazonas, Manaus, 2013.

CORREIO DA AMAZÔNIA. Escola Estadual de Educação Especial 'Manoel Marçal', reinaugurada em Manaus. Disponível em: <https://correiodaamazonia.com/escola-estadual-de-educacao-especial-manoel-marcal-reinaugurada-em-manaus/>. Acesso em dez. 2017.

COSTA, C. André Vidal de Araújo: o homem, o humanista e o social. Manaus, 2010. Disponível em: $<$ http://www.recantodasletras.com.br/artigos/2609897> . Acesso em: out. 2017.

FENAPAES. Apae Brasil: Federação Nacional das Apaes: nossa história. Disponível em: $<$ http://apaebrasil.org.br/page/2>. Acesso em jan. 2018.

FIDELIS, B. S; MIKI, P. S. R. História da Associação de Pais e Amigos dos Excepcionais em Manaus-APAE. In: ENCONTRO PARA AS POLÍTICAS PÚBLICAS PARA A PAN-AMAZÔNIA E CARIBE, 4., Boa Vista..Anais...Boa Vista: EDUFRR, 2017.

FIGUEIRA, E. O que é educação inclusiva. São Paulo: Brasiliense, 2011 (Coleção Primeiros Passos).

INSTITUTO FEILIPPO SMALDONE. Histórico do Instituto. Disponível em: < http://institutofilipposmaldone.com.br/manaus/instituto-filippo-smaldone/>. Acesso em: mai. 2018.

JANNUZZI, G. M. A educação do deficiente no Brasil: dos primórdios ao início do século XXI. Campinas: Autores Associados, 2004. 
JANNUZZI, G. M. CAIADO, K. R. M. Apae: 1954 a 2011: algumas reflexões. Campinas, SP: Autores Associados, 2013.

LAPLANE, A. L. F.; CAIADO, K. R. M.; KASSAR, M. C. M. A relações público-privado na Educação Especial: tendências atuais no Brasil. Revista Teias, Rio de Janeiro, v. 17, n. 46, jul./set. p. 40-55, 2016.

LIMA, E. C. V. Gestão Escolar e Política Educacional de inclusão na rede de ensino municipal de Manaus: uma reflexão à luz da teoria crítica. 2016. 142f. Dissertação (Mestrado em Educação) Universidade Federal do Amazonas, Manaus, 2016.

MANAUS. Lei $n^{\circ} 1.102$, de 09 de março de 2007: cria o Complexo Municipal de Educação Especial André Vidal de Araújo e dá outras providências. Diário Oficial do Município de Manaus no 1679. Manaus, AM, 08 mar. 2007.

MARQUES, M. P. S. D. O Acesso de Pessoas com Deficiência ao Sistema Público de Ensino de Manaus na Percepção dos Professores. 2010. 149f. Tese (Doutorado em Ciências: área Psicologia) - Faculdade de Filosofia, Ciências e Letras de Ribeirão Preto, Universidade de São Paulo, Ribeirão Preto, 2010.

MATOS, M. A. S. Cidadania, diversidade e educação inclusiva: um diálogo entre a teoria e a prática na rede municipal de Manaus. 2008. 229f. Tese (Doutorado em Educação) - Faculdade de Educação, Universidade Federal do Rio Grande do Sul, Porto Alegre, 2008.

MAZZOTTA, M. J. S. Educação Especial no Brasil: história e políticas públicas. 5. ed. São Paulo: Cortez, 2005.

MENDES, E. G. A radicalização do debate sobre inclusão escolar no Brasil. Revista Brasileira de Educação. Rio de Janeiro, v. 11, n. 33, p. 387-405, set./dez., 2006.

MENDES, E. G. Breve histórico da Educação Especial no Brasil. Revista Educación y Pedagogía, v. 22, n. 57, mai./ago., 2010.

MORAES, E. M. G. O sentido da deficiência para as mães de um grupo de crianças de um Programa de Estimulação Essencial da cidade de Manaus. 2011. 107f. Dissertação (Mestrado em Psicologia) - Faculdade de Psicologia, Universidade Federal do Amazonas, Manaus, 2011.

NASCIMENTO, A. C. A.; OLIVEIRA, K. B.; MARINHO, M. F. B. Educação Inclusiva no Contexto Amazônico: formação de professores. Manaus: EDUA, 2007.

OMOTE, S. Normalização, integração, inclusão... Ponto de vista: revista de educação e processos inclusivos. Florianópolis, v. 1, n. 1, jul./dez., 1999. 
ONGS BRASIL. ONGs em Manaus. Disponível em: $<$ http://www.ongsbrasil.com.br/default. asp>. Acesso em: jan. 2017.

PESSOTTI, I. Deficiência mental: da superstição à ciência. São Paulo: T. A. Queiroz Editor, EDUSP, 1984.

PESTALOZZI. Plano de Trabalho: Associação Pestalozzi do Amazonas - Edital n 001/2016/ SEPED. Manaus, 2016.

RECH, T. L. A emergência da inclusão escolar no Governo FHC: movimentos que tornaram uma "verdade" que permanece. 2010. 183f. Dissertação (Mestrado em Educação) - Programa de Pós-Graduação em Educação, Universidade do Vale dos Rios dos Sinos, São Leopoldo, 2010.

SÁ, N. P. Escola de surdos: avanços, retrocessos e realidades. 2011. 223f. Dissertação (Mestrado em Educação) - Faculdade de Educação, Universidade Federal do Amazonas, Manaus, 2011.

SANTOS, L. M. A política pública de educação do município de Manaus: o atendimento educacional especializado na organização escolar. 2011. 209f. Dissertação (Mestrado em Educação)

- Faculdade de Educação, Universidade Federal do Amazonas, Manaus, 2011.

SILVA, R. M. Para além do discurso oficial das políticas públicas: possibilidade de (re) pensar o paradigma de inclusão escolar para o educando com transtorno do espectro autista na cidade de Manaus. 2013. 91f. Dissertação (Mestrado em Educação) - Faculdade de Educação, Universidade Federal do Amazonas, Manaus, 2013.

SOUZA, D. P. Políticas públicas e a visibilidade da pessoa com deficiência: estudo de caso do Projeto Curupira. 2014. 197f. Tese (Doutorado em Educação) - Faculdade de Educação, Universidade Federal do Amazonas, Manaus, 2014.

VINENTE, S. Política e organização pedagógica do serviço de Atendimento Educacional Especializado em Manaus. 2017. 176f. Dissertação (Mestrado em Educação Especial) - Centro de Educação e Ciências Humanas, Universidade Federal de São Carlos, São Carlos, 2017.

Enviado em: 08 de março de 2019

Apreciado em: 11 de abril de 2019

Inserido em: 23 de abril de 2019 